\title{
Smart Cities, Big Data, and Sustainability Union
}

\author{
Sonali Kudva ${ }^{1}$ (iD) and Xinyue Ye ${ }^{2, *}$ \\ 1 College of Communication and Information, Kent State University, Kent, OH 442420, USA; \\ skudva@kent.edu \\ 2 Department of Geography, Kent State University, Kent, OH 442420, USA \\ * Correspondence: xye5@kent.edu; Tel.: +1-419-494-7825
}

Received: 20 August 2017; Accepted: 26 September 2017; Published: 29 September 2017

\begin{abstract}
Media convergence has changed relationships between existing technologies, industries, markets, and audiences. Smart cities are seen as the logical outcome of media convergence. Big Data form the basis and the output of smart technologies. In the last twenty years, there has been much discussion on smart cities, big data, and the need for sustainability in technological endeavors. This article combines these by providing an overview of the three subjects about their points of intersection. Identifying these points of intersection will help smart city researchers to better understand where there is need for further development towards better standards of living and increased sustainability. This review will provide directions for further research and provide a brief historical overview of how far research has come in the three intertwined identified areas towards designing, adapting, and managing smarter communities.
\end{abstract}

Keywords: smart cities; big data; sustainable cities; urban spaces; technology

\section{Introduction}

There is little doubt that the last twenty years have seen tremendous strides in technology and media convergence. Simply put, media convergence is a process that alters the relationship between existing technologies, industries, markets, genres, and audiences. Jenkins studied the convergence of media from three perspectives: the human body enabling face-to-face communication, the technologically reproduced means of mass communication that was one-way; and, the new digital technologies that allow for networked interaction on a one-to-one, one-to-many, and many-to-many types of communication [1]. The ubiquity of technology in virtually every aspect of our-mostly urban-lives has been labeled as "everyware" by one researcher [1,2].

The networked interaction between devices and systems has broadened the reach of technology, even as devices have become smaller, and more multi-functional-fitting in the palm of one's hand. Media convergence may have begun with a kind of loosely-woven net of relationships between the various media technologies, rather than a fully integrated system, but the pieces are in place for agents of media convergence to now function as a well-oiled behemoth unit. This of course, cannot come without the cultural shifts, the legal battles, and the economic consolidations, which will hopefully soon settle down, and move towards what some have seen as a logical conclusion of convergence-the creation of smart spaces, where technology and daily life are irrevocably merged [1].

This paper first examines some different definitions of smart cities, and the way they are being enacted, then moves on to take a look at an important byproduct of a smart city-Big Data. Finally, it will provide an overview of how smart cities and big data could work in tandem to contribute to more sustainable communities. This overview will help researchers identify points of intersection in these three areas of study for further development and improvement, which will in turn contribute to better standards of urban living in the long run. 
The purpose of this review is to recognize and acknowledge the obstacles in the realization of sustainable urban spaces through an examination of both smart cities and Big Data. In doing so, it adds to the larger body of literature contributing to urban development and planning.

\section{Smart Cities: How Far We've Come}

The term "smart" is "peculiarly American", because of its pervasive use in everyday speech to refer to people and ideas that provide intelligent insights [3]. It has only recently come to be used in urban planning to denote the growth of a city from its traditional sprawl to a more efficiently functioning unit. Simply put, a smart city [4,5], (or wired city [6,7], cybercity [8], digital cities [9], intelligent city, sustainable city [10], virtual city, or information city) is one where Information and Communication Technologies work alongside traditional infrastructure, and integrating digital technology in a way that improves the quality of life. Cocchia [11] has asserted that the notion of a smart city came about as a result of the objectives established by the Kyoto Protocol from 1997, which labeled certain initiatives and projects concerned with the development of cities as "smart." A smart city may also be thought of as an organic interdependent system of networks [3,12]. Greenfield [2] understood the notion of smart city as the phenomenon that urban life is now increasingly "everyware". What this indicates is that the foundations of the smart city include an intelligent connected physical infrastructure, social infrastructure, and business structure, all of which combine to use the collective intelligence in the best possible way to improve the standard of living [13]. The intelligent network allows for the monitoring and integration of all critical infrastructure, better optimization of resources, planning of preventative maintenance activities, and increased security [14]. Analyzing the information collected through the devices that make up the technological infrastructure of "everyware" could help provide a more cohesive understanding of urban spaces, further contributing to enhanced efficiency and sustainability in urban life, while still promoting civic participation and access [15].

One of the most thorough discussions on the topic of smart cities remains a review by Annalisa Cocchia [16], of all the work done in defining smart cities-and the consensus appears to be that there is no consensus, a view that has been echoed by other researchers who have said that the idea of a smart city is one that is largely inconsistent, an urban labeling phenomenon, and moreover one that remains largely conceptual [4,16]. But perhaps one reason Cocchia's [16] systematic review was so successful, was because it separated the review into the study of smart cities into: understanding the word "smart" as connected to technology and urban development; followed by understanding how "smart cities" have been defined thus far; and finally a discussion used by certain prominent researchers in this area [16].

Neirotti, De Marco, Cagliano, Mangano, \& Scorrano [17] conducted an empirical study on the role of various contextual factors play in the development, planning, and functioning of smart cities. This seminal work looks at the role of economic, urban, demographic, and geographical factors (including local cultural contexts) on the planning approach of a smart city through an analysis of the coverage ratio of smart city initiatives to the extent of their application domains [17]. The findings from this study indicated that smart city initiatives are not the same worldwide, and are largely dependent on local governments and cultures. Thus, the development of smart cities has remained uneven and there is no dominant design pathway. Instead, economic development and other structural contextual variables are more important in determining smart city development and planning. And finally, the study found that many smart city municipalities and their technology vendors favor investment in technology over people, which is sometimes detrimental when trying to create a more sustainable, easier standard of living [17].

The creation of a "smart city" implies the use of technology to increase the quality of life in urban spaces, both improving environmental quality and offering more efficient services to citizens [18]. A smart city is one where there is a network of intelligent instruments that are interconnected [13]. The internal workings of the smart city have been compared to a nervous system where digital telecommunication networks constitute the nerves, embedded intelligence are the brains, the sensors 
and tags embody the sensory organs, and where the software represent the knowledge and cognitive competence [12]. Pardo and Nam [19] state that definitions of "smart cities" have been limited to three dimensions: the technology dimension, the human dimension, and the institutional dimension. The technological dimension comprises mainly of the technology infrastructure necessary for the development of smart cities, while the human dimension of the definition usually emphasizes the people, society, education, and knowledge which are all fundamental to the development of any urban area [19]. And lastly, the institutional dimension includes the governance and policy aspects of urban development [19].

Dameri and Cocchia [9] stated that there are three aims to any smart city: to improve environmental quality in urban development, thereby reducing carbon dioxide emissions, traffic congestion and waste; to optimize energy consumption through increasing efficiency and renewable energy production; and, to increase the quality of life, including better public and private services, in areas such as transport and health services. The smart city is one which aspires for its future, a better economy, diversity of its citizens, good governance, increased mobility, and includes the environment and standard of living. It is created through the endowments and activities of its socially aware citizens [20]. There have been six dimensions that have been associated with the creation of smart cities, namely, the economy, people, governance, mobility, environment, and the standard of living [20].

However, cities can only "become" smart, if there are intelligence functions that can integrate and synthesize the data created by them purposefully, and can find ways to improve the efficiency and quality of life for all its citizens [3]. Caragliu, Del Bo, and Nijkamp [5] have defined the smart city as one where good management of natural resources, social participation, and investments in human and social capital, transport, and ICT infrastructure, fuel economic growth and quality of life. Another definition of a smart city identify four components: the people systems (consisting of social and human networks of the local demographic); the business systems (policy and regulations); the transport systems (the movement of goods, services and people); and, information systems (including telecommunications and ICT) [13].

A technical definition of a smart city state that it is an urban space where ICT and Web 2.0 technology are combined, and include other organizational, design and planning efforts to dematerialize and speed up bureaucratic processes and assist in identifying innovative solutions for better city management for increased standards of living [21]. This definition of a smart city implies the development of a knowledge economy within urban spaces, emphasizing the human contribution to smart cities over the technology side. Lessig [22] indicates that most social systems are primarily regulated by four forces, namely, market, law, social norms, architecture, or technology. Smart cities are similarly governed by these four forces, and indeed most of them have become indelibly intertwined with technology and the collection of Big Data [5]. Thus, a smart city is a collection of smart computing technologies-a collection of new network technologies that provide real time views of the world and advance analyses that optimize business process - that may be applied to critical infrastructure components and services [21].

It emerges thus, that there are two major perspectives to understanding smart cities: from the perspective of the technological infrastructure, and from the perspective of social capital and knowledge management $[4,5,17,23]$. Naturally, the process of the creation and running of a smart city involves huge amounts of automated computing, and generates vast amounts of data that are stored and can be analyzed simultaneously. These vast amounts of data are known as "Big Data", a term that is now ubiquitous.

\section{Big Data and Smart Cities}

The simplest way to provide context to understanding the term "Big Data" is to know that it is data that exceeds the processing capacity of conventional database systems (like ledgers and Microsoft Excel files); it is bigger, moves too fast, or doesn't fit database architectures. Thus, value must be extracted from it by processing it correctly [24]. Big Data is always seen in context to the tools that 
allow it to be processed. In fact, Big Data has driven the development of the tools needed to understand it, in terms of hardware, software, and mathematical methods [25].

The collection of "Big Data" in the urban setting is not a new phenomenon by any means. Developments within industrialized societies, like its technologies have always been monitored and recorded. Early versions of "Big Data" included records kept by towns and by churches about local inhabitants [26]. Such data was analyzed for better understanding and to provide direction for the future. It was earlier collected manually in analog formats, but developments in electronic technologies changed all of that. Today, most urban "Big Data" are gathered through the multiple sensors that work automatically, routinely and quietly within a city [25]. "Digital miniaturization" changed the face of Big Data collection forever [25]. And while traffic information was the first automatically sensed and collected data within the urban setting, today, this has reached new heights, with geo-positioning technology available in almost all portable devices. Even today, the largest component of "Big Data" continues to remain data concerned with human mobility, thanks mostly to satellite-enabled Global Positioning Systems. This, combined with telecommunications records, social media and other demographic information could provide unique insight into human movements, daily lives, and habits [25]. And, in the next few decades, most large-scale urban data will originate from digital sensors embedded in all our electronic devices. This will be in many forms, complete with temporal and geo-spatial tags [25]. Similarly, while the planning of smart cities has attracted considerable attention in recent times, there has been some expectations that Internet Service providers (who are Big Data aggregators) will become drivers and enablers of innovation in areas of health, defense, environment, and commerce [27].

Boyd and Crawford [28] have defined Big Data as a cultural, technological, and scholarly phenomenon that is based on an interplay between technology, analysis, and mythology. The technological aspect refers to the algorithmic tools used for analysis, the analysis itself helps to discern patterns used for making predictions based on mathematical computations, and the mythology means to state the inherent belief that human beings hold about large banks of data as having the capacity to provide insight with some amount of credibility, objectivity, and accuracy [28]. The instruments that make up the smart city help in the collection of big data through the capture and integration of live real-world information using sensors, kiosks, meters, personal devices, appliances, cameras, smart phones, implanted medical devices, the web, and other similar data-acquisition systems (including social networks) [12]. The interconnection of these instruments allows not just for the collection, but also the processing of this data into an enterprise computing platform and enables the sharing of the data between city facilities and services [12]. The intelligence aspect of these instrument refers to the inclusion of complex analytics, modeling, optimization, and visualization in the operational business processes, that help authorities make better operational decisions [12].

Big Data has been characterized by certain features: massive in size; created and collected rapidly in real time; diverse in its variety—being both structured and unstructured; exhaustive in its scope, as it endeavors to collect data from the most amount of people at any given time; highly detailed; relational, even as the data may be conjoined and interconnected; and, flexible in that it may be molded differently in terms of size and field [29,30].

One of the most well-known studies in Big Data is a study done by Google that predicted the spread of the winter flu (H1N1) in the United States. To do this, Google compared data from common search terms by users between 2003 and 2008, and data provided by the Center for Disease Control. The results of analysis made predictions about the spread of the flu in later years [31]. And while, in recent years there has been criticism of the study and its inaccuracies, there is no doubt that the analysis of Big Data can be valuable [26,29]. Today, there are also other concerns about the infallibility of Big Data, including its vulnerabilities to hackers, and of course to being (mis)interpreted to serve the interest of big business and politics [30]. What this means is that Big Data, though inherently impartial, cannot exist or be comprehensible without the ideas, techniques, and technologies wielded by those who conceive, process, or analyze the data. Thus, it may be framed or interpreted to serve political or 
corporate interests that may not always reflect its true nature [30]. There have also been questions on increased surveillance, and the risks of the data collected falling into the wrong hands through hacks and other vulnerabilities [30].

An ongoing long term study by Robert J. Sampson on the city of Chicago is a more recent example of the many applications of Big Data in understanding vast populations, and the problems, issues, and successes of diversity in neighborhoods. In the study, Sampson has examined data gathered from interviews, surveys, and city demographic data to craft revised theories of culture, criminology and neighborhood concepts [32]. These revised theories combined with the inferences from Big Data reveal interesting things about diversity, increased immigration, crime statistics and the future of Chicago in the USA overall. These conclusions can aid in city planning [32]. A combination, or a fusion of Big Data collected by various departments could help in the smarter use of resources, creating a higher standard of living, and providing greater transparency to local citizens [33]. Thus far, however, such endeavors for data sharing have been few and far between, and have not been successful.

Large corporations have been analyzing and using Big Data for some years, and there are five major ways in which they have managed to create more value and increase efficiency using big data. For instance, corporations can use Big Data to increase transparency. Through the wide variety of data collected, they may be able to use big data for understanding performance better, which in turn can boost productivity and performance. Big Data analysis can also help companies make better management decisions and make more accurate forecasts, while focusing in on their target markets and offering great customization possibilities. This leads to better products and more efficient marketing [34]. An important way in which Big Data may be used by Smart Cities and for the creation of more sustainable urban spaces is through the use of the collected Big Data to be analyzed for use to create more efficient and better supportable systems for the future [30]. For instance, cities that collect real time data can be said to be better prepared for extreme weather conditions, and can deal with emergencies in a more timely, efficient way rather than areas where such data is not collected in real time.

The application of Big Data in making cities smarter has been studied and enumerated by some researchers [35]. These have been invaluable in understanding the various applications of Big Data in improving urban living in the areas of transportation, power grids, smart education, energy, healthcare, waste management, relief work, and defense (Figure 1). Three broad categories of sources of Big Data may be identified through a review of the literature: directed, automated, and volunteered [29]. Directed data are produced by forms of technology that are focused on places, or individuals (or groups of people), and are operated by humans. This would include forms of surveillance used by authorities in different areas of law enforcement, waste management, effective resource management. Automated data are inherently produced by devices or systems in due course of their functioning. This would include smartphones, satellite television systems, aircraft radar systems, and the like, which automatically collect and transmit data. Finally, volunteered data are products of user-generated systems like social networks [31]. The analysis of Big Data has already provided results for more efficient functioning of cities in several areas including crowd control and conservation of resources. The LED lights of Los Angeles and the Los Angeles landscaping have both been results of Big Data analysis which help conserve water and electricity [36]. Meanwhile, the shape of Shanghai's Museum of Natural History was designed for more effective crowd control [36]. And lastly, Saudi Arabia makes use of Big Data in order to control and provide for the large crowds that descend upon the country during the holy month of Hajj [36]. Thus, there is no question that the analysis of Big Data in the urban setting has definitely improved the quality of life. However, while these successes must be celebrated, it must not be forgotten that Big Data initiatives can only be termed successful if they are sustained and upheld in the long term, and interpreted accurately and without bias. 


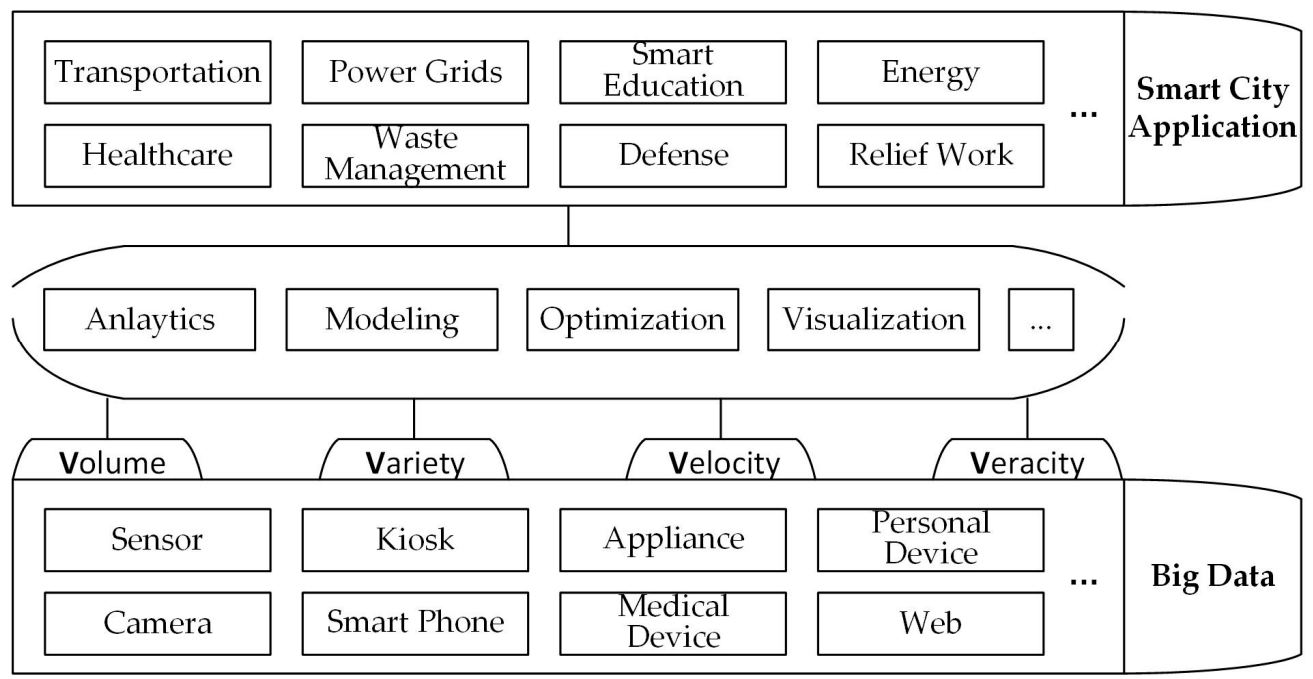

Figure 1. Big Data for Smart City Application.

\section{The Smart Cities Initiative}

The National Smart Cities Initiative was set up in 2015 to help communities tackle local challenges and improve city services, and received additional funds in 2016 [37]. Also aligned with the National Smart Cities Initiative is the Smart \& Connected Communities (S\&CC) effort with the participation from the NSF Directorates for Computer and Information Science and Engineering (CISE), Education and Human Resources (EHR), Engineering (ENG), Geosciences (GEO), and Social, Behavioral, and Economic Sciences (SBE) [38]. The purpose of the Smart \& Connected Communities is to address challenges through fundamental research, building capacity for research, and transforming research into practice, while improving the quality of life in communities (Figure 2). Some of the advancement goals within the S\&CC are: new methods and technologies for leveraging data; advances in modeling and design of complex sociotechnical systems; research in the dynamics, characteristics, and behaviors of individuals and communities; and, the development of new methods and technologies to support education and workforce development [38].

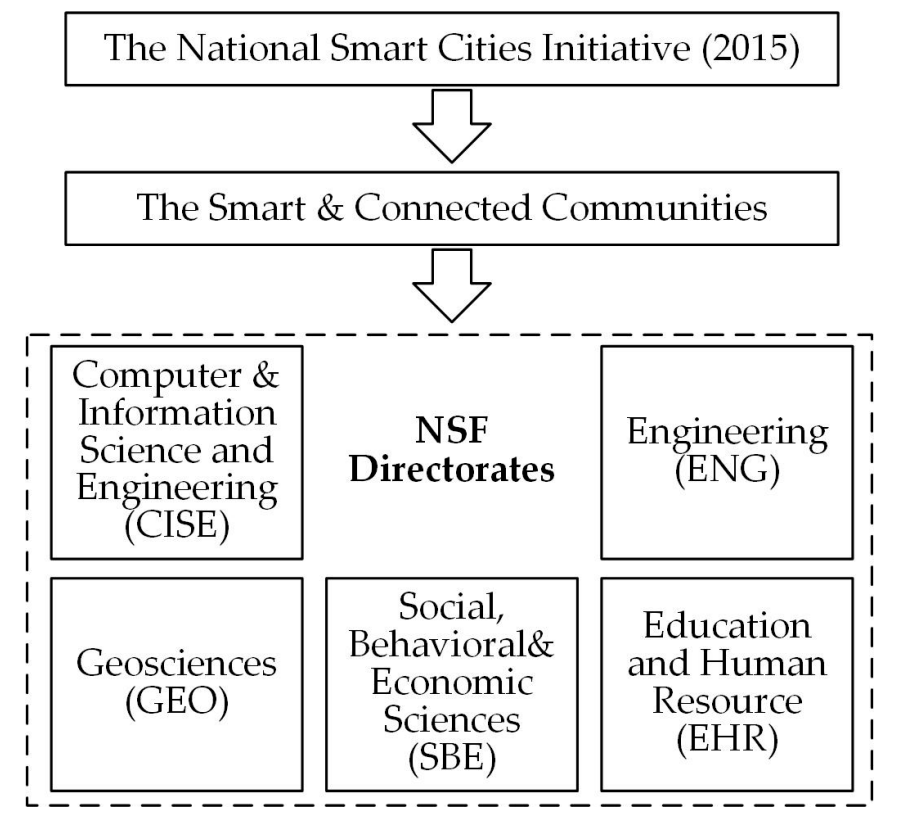

Figure 2. Grants Related to Smart and Connected Communities. 
Cyber-physical systems are transforming how people interact with engineered systems by integrating sensing, computation, control, and networking into physical objects and infrastructure, as well as connecting these objects to the Internet and to each other. These systems could reshape social systems and environments into more responsive, precise, reliable, and efficient systems, enabling a revolution of "smart" devices and systems [39].

Some of the NSF investments in support of the Smart Cities initiative include: the Smart and Connected Communities, the US Ignite Program, new Partnerships for Innovation: Building Innovation Capacity, Cyber-Physical Systems, "Spokes" — extending the Big Data Regional Innovation Hubs, Smart and Connected Health Research, Big Data Research, the Global City Teams Challenge, and funding for new research and capacity building awards supporting lifelong learning [38]. The NSF also announced in early 2017 that Amazon Web Services (AWS), Google, and Microsoft will participate in its new Critical Techniques, Technologies and Methodologies for Advancing Foundations and Applications of Big Data Sciences and Engineering (BIGDATA) research program. The three major cloud providers will supply cloud computing technology and infrastructure to qualifying NSF-funded projects, including the Smart Cities Initiative [40]. The NSF funded regional Data Hubs, in the Northeast, South, Midwest, and West use Data Science resources to address challenges like agriculture, healthcare, and the development of smart cities [40].

The Smart and Connected Health ( $\mathrm{SCH}$ ) Program is a combination of the Smart Cities Initiative and the Big Data Initiative, and is supported by multiple federal agencies, including the National Science Foundation and the National Institutes of Health. The goal of the program is to initiate transformation of the healthcare system from reactive and hospital-centered to preventative, proactive, evidence-based, patient-centric solutions that are more focused on overall well-being, rather than disease and illness [41]. Thus, the focus of this program is to facilitate the development of next-generation healthcare solutions and to encourage new and existing research communities to focus on generating ideas adding value to health services, including but not limited to sensor technology, networking, information and machine learning technology, decision support systems, modeling of behavioral and cognitive processes, as well as system and process modeling [41]. These developments would naturally have to function within the parameters of other social systems and satisfy clinical/medical needs, social interactions, cognitive limitations, barriers to behavioral change, heterogeneity of data, semantic mismatch, and limitations of current cyber-physical systems [41].

\section{Big Data, Smart Cities, and How They Add up to Sustainable Communities}

Half the population on this planet today is estimated to live in an urban environment, and this has led to an increased demand for urban living benefits, including better access to facilities like sanitation, electricity, and technology, among other things [42,43]. But, along with better living conditions and facilities have come greater impacts on the environment and the climate, to which more efficient solutions are needed. Scientists have suggested that quickly advancing technology may provide solutions, combined with more collaborative efforts between various urban departments, including city governments, police forces, health departments, and civil services. The goal of these efforts is to create more sustainable living and less of an impact on the planet, or sustainable development (Figure 3).

Sustainable development is generally considered within three areas: social, economic, and ecological or environmental. Essentially, sustainable development has been defined as requiring social and economic change while reducing the need for environmental protection [44]. Thus, sustainability has three components, namely, the environment, society, and the economy [44]. However, a sustainable community also requires long-range foresight and short-term adaptability in order to become reality [37].

Sustainable communities and the idea of smart cities or digital cities have become synonymous, and there are those who believe the goals of a sustainable community are intrinsically bound. For better understanding, it may be essential to understand the differences between a digital city and a smart city. A digital city is based on ICT and, more specifically, the internet, where the aim is to supply 
information and e-services to citizens and to provide a channel of communication between citizens and administration [9]. On the other hand, a smart city is one that is more driven towards sustainability goals, where investments in human and social capital, as well as traditional (transport) and modern ICT infrastructure fuel sustainable economic growth, and a higher quality of life, while still utilizing natural resources most efficiently through participatory governance [5]. The difference between the smart city and the digital city and the impact on sustainable communities, forms the substance of a study by Dameri \& Cocchia [9]. Researchers for this study look at the evolution of the terminology of "smart" and "digital" cities respectively, and finally conclude that the two are distinctly different approaches, and that a combination of the two would make the realization of sustainable and smart communities easier [9].

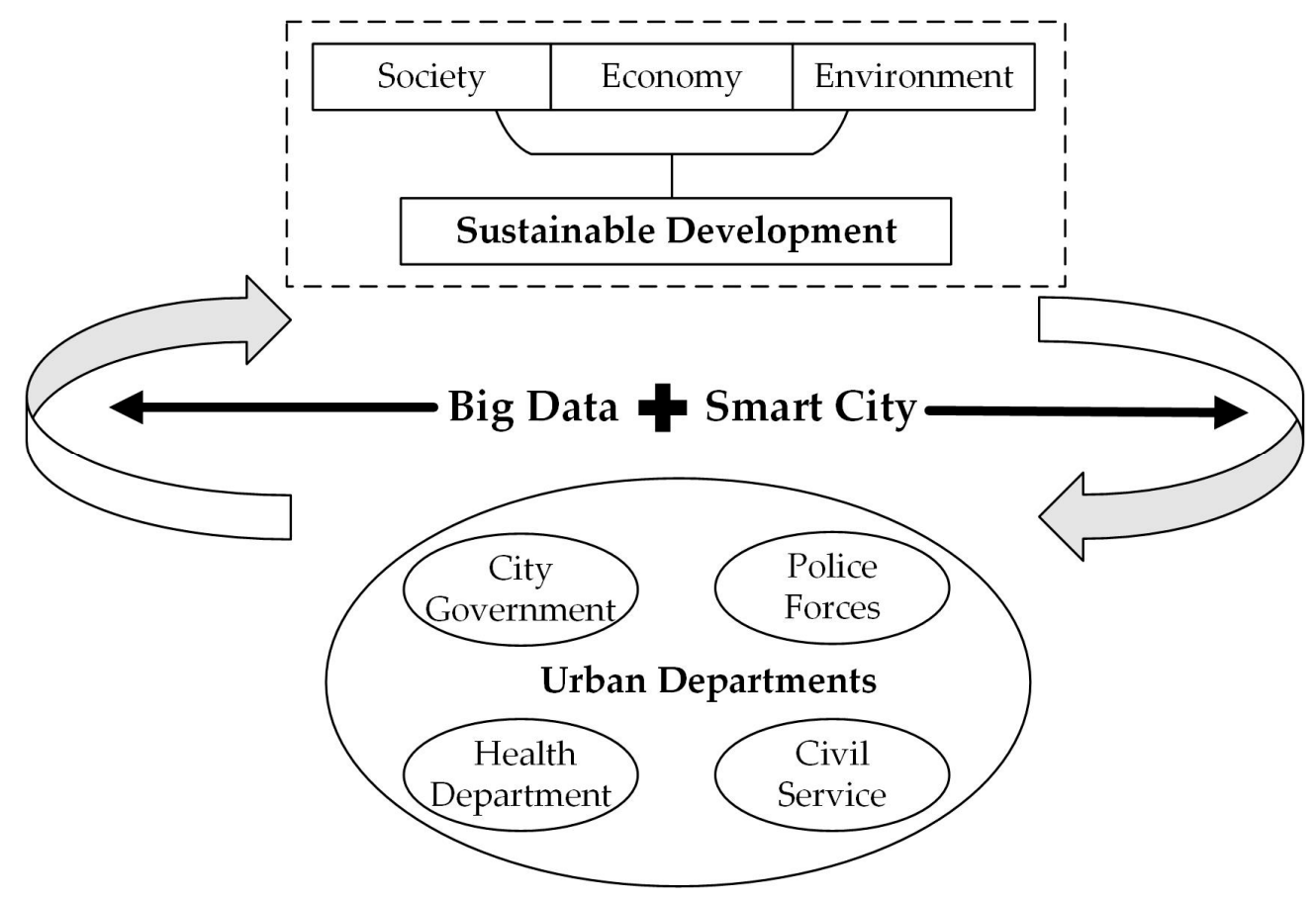

Figure 3. Big Data and Smart City for Sustainable Development.

However, while sustainable goals are admirable, their development has been slow, and sustainable communities have been difficult to attain. Most of the world's resources are consumed in cities worldwide, and the most amount of environmental damage is felt through urban living [42]. One of the main reasons for this is cost. In the United States alone for instance, over $\$ 350$ billion has been estimated as spent in the last 25 years on just the maintenance of the 285,000 towers that facilitate the wireless bandwidth within the country [15]. Urban living is expensive and dependent on the vagaries of local government, which change every few years. Cities consume up to 80 percent of energy produced worldwide, and are largely responsible for CHG emissions [42]. This has been a great impediment to the development of smart cities overall.

Companies like Cisco, IBM, Microsoft, Facebook, HP, and other such companies have attempted to launch their own plans for a "smarter" planet [43]. They have in some cases been strong advocates for the creation of smart city development, on the one hand because such cities are great exhibits for adoption of their technologies, and on the other because of the opportunities such urban spaces provide for the investment in human capital [30]. The companies seek deregulation, privatization, and more open economies that enable more efficient capital accumulation and the cities themselves would serve as centers of innovation and further urban development. Hollands [4] has identified five main characteristics of a smart city: an embedded ICT infrastructure into the urban life, corporation-led urban development with a neo-liberal approach to government; a focus on social capital; the adoption 
of a community agenda with a focus on social learning and education; and an overall emphasis on social and environmental sustainability. However, this could lead to an inevitable conflict of interest when serving the interests of the various kinds of urban dwellers, like the ordinary class, the elite, and the governing bodies [4]. This indicates that the road to smarter sustainable cities has been rocky. In some cases, it has been the very human characteristics of corruption and greed that have prevented sustainable growth. For instance, the Bhoomi Project in India, which was to prevent large landowners from monopolizing land buying by bribing officials. While the project may have shown results where official reports of corruption were lowered, it was also evident that the digital divide between those with access to technology and those who didn't widened considerably [15].

The European Union (EU) has begun investigating plans to build more sustainable communities. A big part of the reason for the failure of earlier initiatives, it has been suggested is due the emphasis on economics and the growth of interconnectivity, rather than emphasis on community efforts to achieve sustainable living [45]. Instead, a commission within the EU is working to promote energy efficiency, renewable energy, green mobility, and lower emissions. Efforts that are successful in this arena are provided funding for further growth and expansion. More efforts have also been set in motion to encourage community efforts in the same direction. It has also been pointed out that mid-level or Tier 2 cities are more suitable for the building of smart cities as they are more viable for overall growth and not quite as plagued by set bureaucracies [45]. In an article on the methodology for planning and analysis of smart cities within the EU, some researchers pointed out that the fuzzy logic model worked best in assessing and understanding [45]. This method considers time contexts, and societal participation within the efforts towards smart cities.

\section{Conclusions}

The revolution of smart devices and Big Data, as well as the cooperation between the various parts of a city could someday lead to the goal: Smart and Sustainable Cities. However, there are many obstacles to overcome in the meantime: human factors like inequalities in wealth and education; infrastructure deficiencies; the impermanence of local governments, combined with the vagaries of current bureaucracies and corruption; and the Digital Divide. Smart Cities are bound by legacy socio-economic-political systems, and their development is impeded by these same systems. Research is limited in the area of examining the obstacles that impede the success of smart city endeavors. And there are a number of reasons for this paucity of research.

Sampson [46] has talked about the increasing fragility of city spaces under rapid urbanization, which has resulted in an emphasis on sustainability efforts in modern infrastructures. However, neighborhood inequalities in contemporary life influence both environmental and social elements that influence sustainability [46]. Local governments in turn, adopt initiatives that are directly in reaction to these inequalities in the short term - rather than being focused on smart city structures, which would and could help eliminate these inequalities. Thus, Sampson [46] asserts that there is a need for more understanding of neighborhood inequalities and related factors, and reiterates the need for new measurement practices and procedures that will better help in the development of more sustainable smart cities.

Research is limited in general on the obstacles in the success of Smart Cities and sustainability. While research mentions the obstacles in isolation as snapshots in specific instances, there is no research that records the success and failures on a sustained basis. This failure, is perhaps for the uneven implementation of Big Data endeavors as a whole. For instance, while Big Data is collected in a number of fields, including geo-spatial data, radar systems, telecommunications, and information systems, there is a distinct lack of data fusion-meaning data is not shared meaningfully between endeavors in these fields. And, researchers have pointed out that the lack of such shared endeavors has enabled continued human tragedy [33]. Smart, sustainable, and better urban living can only be achieved by working together across the government across various scales, along with private and international partners through engaging researchers across disciplines and stakeholders. Learning 
from historical endeavors and carrying out improvements on a sustained basis would also contribute to future success.

And while the collection of Big Data has been emphasized in many settings and locations, the processing of the data has seldom been discussed. Data collected by devices is usually not in the right format for data analysis. Data analysis itself is a process now that is automated, with some amount of human-computer interaction. This requires the use of specific hardware and software that can deal with large amounts of data. It requires skilled manpower to be able to operate the systems. And finally, there is the interpretation of the results. Similar to the collected data, the results similarly need to be formatted to be easily understood by the average layperson [47]. Further, the computational power required to process, store, and collect the data on a continuous basis is not cheap. Upkeep of these systems only adds to the cost.

As stated, there are two major perspectives to understanding smart cities: from the perspective of the technological infrastructure, and from the perspective of social capital and knowledge management $[4,5,17,23]$. A similar statement may be made to understand the value of Big Data and its processing. And thus, it follows that similar approaches must be used in research to categorize and examine smart and sustainable urban space endeavors. Urban research also requires the collaboration of multiple social and technological scholars, and the need for local city planners and administrators to collaborate with the researchers. A successful smart cities initiative would bring together diverse researchers from varying disciplines alongside community leaders and stakeholders; who will conduct research by integrating digital tools, and engineering solutions for the physical world in the fields of health and wellness, energy efficiency, building automation, infrastructure and public safety, including advanced networking and connectivity, sensing, real-time data analytics, control, automation and decision-making; and then collaborating with local city administrators and planners to transition these technologies to widespread use.

In the meantime, more research and insights are needed on catalyzing the Smart and Sustainable Cities revolution by way of understanding the results of analyses of Big Data, as well as facilitating and encouraging the cooperation between neighbors, neighborhoods, and departments within cities and between cities to create continuously improving infrastructure and to increase understanding. This understanding of cities and communities is required in order to improve their functioning and quality of life through innovation in computing, engineering, information and physical sciences, social, and learning sciences. "The effective integration of technology and data into decision making and physical infrastructure has the ability to transform society, allowing local cities and communities to overcome physical, social, economic, and infrastructural challenges... " will help measure and shape the pulse of communities' physical and social infrastructures to improve the quality and efficiency of our lives [48].

There is a great deal resting on the potential for better living in sustainable and smart urban spaces. There are also many stakeholders in their creation, their continued upkeep, and their future. It is vital that these stakeholders put their own interests aside to prioritize the city. Corruption and the lack of compromise and coordination between these stakeholders is what has impeded Smart and Sustainable cities [49].

Looking forward, more funding agencies need to leverage longstanding investments, as well as future investments, that engage researchers across multiple disciplines and community stakeholders to solve deeply interdisciplinary, integrative challenges at the interface of social and technological systems [50]. The successful collaboration between researchers, practitioners, and administrators could theoretically build a sustainable community [51-55]. But, with the increased development and integration of technology, the success of sustainable spaces and communities depends on evaluation, measurement, and continued amelioration.

Acknowledgments: This study has been partially funded by National Science Foundation (1416509, 1637242, 1535031). Any opinions, findings, and conclusions or recommendations expressed in this material are those of the author(s) and do not necessarily reflect the views of the National Science Foundation. 
Author Contributions: Sonali Kudva and Xinyue Ye co-designed the research. Both authors read and approved the final manuscript.

Conflicts of Interest: The authors declare no conflict of interest.

\section{References}

1. Jenkins, H. The cultural logic of media convergence. Int. J. Cult. Stud. 2004, 7, 33. [CrossRef]

2. Greenfield, A. Everyware: The Dawning Age of Ubiquitous Computing; New Riders: Berkeley, CA, USA, 2010.

3. Batty, M.; Axhausen, K.W.; Giannotti, F.; Pozdnoukhov, A.; Bazzani, A.; Wachowicz, M.; Ouzounis, G.; Portugali, Y. Smart Cities of the Future. Eur. Phys. J. Spec. Top. 2012, 214, 481. [CrossRef]

4. Hollands, R.G. Will the real smart city please stand up? Intelligent, progressive or entrepreneurial? City 2008, 12, 303. [CrossRef]

5. Caragliu, A.; del Bo, C.; Nijkamp, P. Smart cities in Europe. J. Urban Technol. 2011, 18, 65. [CrossRef]

6. Dutton, W.H.; Kraemer, K.L.; Blumler, J.G. Wired Cities: Shaping the Future of Communications; Macmillan Publishing Co., Inc.: Basingstoke, UK, 1987.

7. Winseck, D. Wired Cities and Transnational Communications: New Forms of Governance for Telecommunications and the New Media. In Handbook of New Media: Social Shaping and Consequences of ICTs; Sage: London, UK, 2002; pp. 393-409.

8. Graham, S. The Cybercities Reader; Psychology Press: Hove, UK, 2004.

9. Dameri, R.; Cocchia, A. Smart City and Digital City: Twenty Years of Terminology Evolution. In Proceedings of the X Conference of the Italian Chapter of AIS (ITAIS), Milano, Italy, 14 December 2013.

10. Deakin, M.; Allwinkle, S. Urban regeneration and sustainable communities: The role of networks, innovation, and creativity in building successful partnerships. J. Urban Technol. 2007, 14, 77-91. [CrossRef]

11. Cocchia, A. Smart and digital city: A systematic literature review. In Smart City; Springer: Cham, Switzerland, 2014; pp. 13-43.

12. Chourabi, H.; Nam, T.; Walker, S.; Gil-Garcia, J.R.; Mellouli, S.; Nahon, K.; Pardo, T.A.; Scholl, H.J. Understanding Smart Cities: An integrative Framework. In Proceedings of the 201245 th Hawaii International Conference on System Science (HICSS), Maui, HI, USA, 4-7 January 2012.

13. Harrison, M. Zhang Yimou's Hero and the Globalisation of Propoganda. Millenn. J. Int. Stud. 2006, 34, 569.

14. Bowerman, B.; Braverman, J.; Taylor, J.; Todosow, H.; von Wimmersperg, U. The vision of a smart city. In Proceedings of the 2nd International Life Extension Technology Workshop, Paris, France, 28 September 2000.

15. Townsend, A.M. Smart Cities: Big Data, Civic Hackers, and the Quest for a New Utopia; WW Norton \& Company: New York, NY, USA, 2013.

16. Cocchia, A. Smart and Digital City: A Systematic Literature Review; Springer: Cham, Switzerland, $2014 ;$ p. 13.

17. Neirotti, P.; de Marco, A.; Cagliano, A.C.; Mangano, G.; Scorrano, F. Current trends in Smart City initiatives: Some stylised facts. Cities 2014, 38, 25-36. [CrossRef]

18. Hall, P. Creative Cities and Economic Development. Urban Stud. 2000, 37, 639-649. [CrossRef]

19. Nam, T.; Pardo, T.A. Conceptualizing smart city with dimensions of technology, people, and institutions. In Proceedings of the 12th Annual International Digital Government Research Conference: Digital Government Innovation in Challenging Times, College Park, MD, USA, 12-15 June 2011.

20. Giffinger, R.; Fertner, C.; Kramar, H.; Kalasek, R.; Pichler-Milanovic, N.; Meijers, E. Smart Cities: Ranking of European Medium-Sized Cities; Final Report; Centre of Regional Science, Vienna University of Technology: Vienna, Austria, 2007.

21. Toppeta, D. The Smart City Vision: How Innovation and ICT Can Build Smart, "Livable”, Sustainable Cities; Think! The Innovation Knowledge Foundation: Milano, Italy, 2010.

22. Lessig, L. Code: And Other Laws of Cyberspace; Basic Books: New York, NY, USA, 2009.

23. Dirks, S.; Keeling, M. A Vision of Smarter Cities: How Cities Can Lead the Way into a Prosperous and Sustainable FUTURE; IBM Institute for Business Value: Cambridge, USA, 2009; Volume 8.

24. Dumbill, E. Making Sense of Big Data. Big Data 2013, 1, 1-2. [CrossRef] [PubMed]

25. Batty, M. Big Data, Smart Cities and City Planning. Dialogues Hum. Geogr. 2013, 3, 274. [CrossRef]

26. Lazer, D.; Kennedy, R.; King, G.; Vespignani, A. Big Data. The Parable of Google Flu: Traps in Big Data Analysis. Science 2014, 343, 1203. [CrossRef] [PubMed] 
27. Kroes, N. The Critical Role of Cities in Making the Digital Agenda a Reality, Closing speech to Global Cities Dialogue Spring Summit of Mayors. In Proceedings of the European Commission-SPEECH/10/272, Brussels, Belgium, 28 May 2010.

28. Boyd, D.; Crawford, K. Critical questions for big data: Provocations for a cultural, technological, and scholarly phenomenon. Inf. Commun. Soc. 2012, 15, 662. [CrossRef]

29. Kitchin, R. Big Data and Human Geography: Opportunities, Challenges and Risks. Dialogues Hum. Geogr. 2013, 3, 262. [CrossRef]

30. Kitchin, R. The Real-Time city? Big Data and Smart Urbanism. GeoJournal 2014, 79, 1-14. [CrossRef]

31. Mayer-Schönberger, V.; Cukier, K. Big Data: A Revolution that Will Transform How We Live, Work, and Think; Houghton Mifflin Harcourt: Boston, MA, USA, 2013.

32. Sampson, R.J. Open Doors Don't Invite Criminals: Is Increased Immigration Behind the Drop in Crime? New York Times, 2016.

33. Alam, F.; Mehmood, R.; Katib, I.; Albogami, N.N.; Albeshri, A. Data Fusion and IoT for Smart Ubiquitous Environments: A Survey. IEEE Access 2017, 5, 9533-9554. [CrossRef]

34. Mckinsey Global Institute; Manyika, J.; Chui, M. Big Data: The Next Frontier for Innovation, Competition, and Productivity; McKinsey \& Company: New York, NY, USA, 2011.

35. Al Nuaimi, E.; Al Neyadi, H.; Mohamed, N.; Al-Jaroodi, J. Applications of Big Data to Smart Cities. J. Internet Serv. Appl. 2015, 6, 25. [CrossRef]

36. Newman, D. Big Data and the Future of Smart Cities. Forbes, 2017. Available online: http://www. forbes.com/sites/danielnewman/2016/08/15/big-data-and-the-future-of-smart-cities / (accessed on 28 September 2017).

37. Mazmanian, D.A.; Kraft, M.E. Toward Sustainable Communities: Transition and Transformations in Environmental Policy; MIT Press: Cambridge, MA, USA, 2009.

38. National Science Foundation. Smart \& Connected Communities: A Vision for the 21st Century. Available online: https: / /www.nsf.gov/ cise/scc/ (accessed on 28 September 2017).

39. National Science Foundation. Cyber-Physical Systems I NSF-National Science Foundation. Available online: https:/ / www.nsf.gov/news/special_reports/cyber-physical/ (accessed on 28 September 2017).

40. Computing Community Consortium. NSF and Big Data Hubs Receive Cloud Credits for Big Data Research; Computing Community Consortium: Washington, DC, USA, 2017.

41. National Science Foundation. Smart and Connected Health INSF; National Science Foundation: Arlington, VA, USA, 2017.

42. United Nations. World Urbanization Prospects: The 2007 Revision; UN: New York, NY, USA, 2008.

43. Vilajosana, I.; Llosa, J.; Martinez, B.; Domingo-Prieto, M.; Angles, A.; Vilajosana, X. Bootstrapping smart cities through a self-sustainable model based on big data flows. IEEE Commun. Mag. 2013, 51, 128. [CrossRef]

44. Roseland, M. Toward Sustainable Communities: Solutions for Citizens and Their Governments; New Society Publishers: Gabriola, BC, Canada, 2012; Volume 6.

45. Lazaroiu, G.C.; Roscia, M. Definition methodology for the smart cities model. Energy 2012, 47, 326. [CrossRef]

46. Sampson, R.J. Urban Sustainability in an Age of Enduring Inequalities: Advancing Theory and Ecometrics for the 21st-Century City. Proc. Natl Acad. Sci. USA 2017, 114, 8957-8962. [CrossRef] [PubMed]

47. Labrinidis, A.; Jagadish, H.V. Challenges and opportunities with big data. VLDB Endowment 2012. [CrossRef]

48. National Science Foundation. NSF Commits More Than $\$ 60$ Million to Smart Cities Initiative; National Science Foundation: Arlington, VA, USA, 2016.

49. Papa, R.; Gargiulo, C.; Cristiano, M.; di Francesco, I.; Tulisi, A. Less Smart More City. TeMA J. Land Use Mobil. Environ. 2015, 8, 159-182.

50. Li, Q.; Wei, W.; Xiang, N.; Feng, D.; Ye, X.; Jiang, Y. Social Media Research, Human Behavior, and Sustainable Society. Sustainability 2017, 9, 384. [CrossRef]

51. Ye, X.; Huang, Q.; Li, W. Integrating big social data, computing and modeling for spatial social science. Cartogr. Geogr. Inf. Sci. 2016, 43, 377-378.

52. Ye, X.; Shi, X. Pursuing Spatiotemporally Integrated Social Science Using Cyberinfrastructure. In Modern Accelerator Technologies for Geographic Information Science; Springer: New York, NY, USA, 2013; pp. 215-226.

53. Liu, J.; Li, Y.; Chen, M.; Dong, W.; Jin, D. Software-Defined Internet of Things for Smart Urban Sensing. IEEE Commun. Soc. 2015, 53, 55-63. [CrossRef] 
54. Chen, M.; Hao, Y.; Hwang, K.; Wang, L.; Wang, L. Disease Prediction by Machine Learning over Big Healthcare Data. IEEE Access 2017, 5, 8869-8879. [CrossRef]

55. Hwang, K.; Chen, M. Big Data Analytics for Cloud/IoT and Cognitive Computing; Wiley: Oxford, UK, 2017; ISBN 9781119247029. 